\title{
COL11A1 is overexpressed in gastric cancer tissues and regulates proliferation, migration and invasion of HGC-27 gastric cancer cells in vitro
}

\author{
AIQING LI ${ }^{1,2^{*}}, \mathrm{JUN} \mathrm{LI}^{1,2^{*}}, \mathrm{JINPING} \mathrm{LIN}^{2}$, WEI ZHUO ${ }^{3}$ and JIANMIN SI ${ }^{1,2}$ \\ ${ }^{1}$ Department of Gastroenterology, Sir Run Run Shaw Hospital, Zhejiang University School of Medicine; \\ ${ }^{2}$ Institution of Gastroenterology, Zhejiang University; ${ }^{3}$ Laboratory of Cell Biology, \\ Zhejiang University School of Medicine, Hangzhou, Zhejiang, P.R. China
}

Received June 30, 2016; Accepted November 21, 2016

DOI: $10.3892 /$ or.2016.5276

\begin{abstract}
The role of COL11A1 in carcinogenesis is increasingly recognized. However, the biological role and potential mechanisms of COL11Al in gastric cancer have not been elucidated. In the present study, the COL11A1 mRNA expression in 57 patients with gastric cancer was measured by reverse transcription quantitative PCR (RT-qPCR), and the biological effects of COL11A1 suppression were determined using MTS, monolayer colony formation, flow cytometry and Transwell assays. In addition, the potential molecular mechanisms of COL11A1 in gastric cancer were analyzed by western blotting and cDNA microarray analysis. Compared with matched adjacent non-tumor tissue, COL11A1 mRNA was significantly overexpressed in tumor tissue and was positively related to age, tumor invasion depth, tumor size and lymph node positivity. Moreover, in vitro experiments demonstrated that COL11A1 suppression by short hairpin RNA (shRNA) significantly inhibited the proliferation, migration and invasion of HGC-27 cells and that COL11AI suppression promoted cell apoptosis, induced $\mathrm{G}_{1}$-phase cell cycle arrest and led to a significant downregulation of cyclin $\mathrm{D}_{1}$ and upregulation of p21 and cleaved caspase-3. In addition, the cDNA microarray analysis of HGC-27 cells with and without COL11A1 suppression indicated that COL11AI may regulate multiple genes responsible for cell growth and/ or invasion, including downregulation of $C D K 6$, TIAMI, ITGB 8 and WNT5A and upregulation of RGS2 and NEFL following suppression of COL11A1 expression in HGC-27 cells, validated with RT-qPCR assays. Taken together, our
\end{abstract}

Correspondence to: Dr Jianmin Si, Department of Gastroenterology, Sir Run Run Shaw Hospital, Zhejiang University School of Medicine, 3 East Qingchun Road, Hangzhou, Zhejiang 310016, P.R. China

E-mail: jianmin_si@zju.edu.cn

*Contributed equally

Key words: gastric cancer, COL11A1, proliferation, invasion, cDNA microarray findings demonstrate that COL11A1 might be an oncogene in $\mathrm{GC}$ and is a promising therapeutic target in cancer treatment.

\section{Introduction}

Gastric cancer (GC) ranks the third cause of cancer mortality and the fifth most common cancer worldwide (1), while most patients with GC are diagnosed at the advanced stage which means a relatively poor prognosis of overall survival (2). As is well recognized, cancer results from accumulation of multiple molecular alterations in the same cells or their descendants (3). Hence, the identification of genes with oncogenic potential or tumor-suppressing activity may be of great use for diagnosis and treatment.

Previously, Zhao et al used an oligonucleotide microarray containing 38,500 genes in 11 patients with GC to distinguish malignant lesions from premalignant and normal ones, and type XI collagen $\alpha 1(C O L 11 A 1)$ gene expression was found upregulated in malignant tissue compared to premalignant tissue (4). As a member of minor fibrillar collagens, COL11A1, encoded by $C O L 11 A 1$ gene located on chromosome 1p21, can be produced by cartilage and a variety of non-cartilaginous tissues, such as bone, vitreous, skin, and heart (5). Alterations of COL11A1, including at least four mRNA variants, can lead to several diseases such as Stickler syndrome type 2 (6), Marshall syndrome (7,8) and lumbar disc disease (9).

Besides, COL11A1 has also been reported to be upregulated in various cancers, including colorectal, pancreatic, and ovarian cancer. Fischer et al first reported that COL11Al mRNA expression was significantly increased in colorectal cancer tissue compared with normal colonic tissue (10), and studies in pancreatic cancer (11), non-small cell lung cancer (12) and breast cancer (13) have also demonstrated increased levels of COL11A1 in tumor tissue compared with normal tissue. Recent studies have implicated COL11A1 in cancer cell growth and tumorigenicity. For example, COL11A1 knockdown in head and neck squamous cell cancer gave rise to a reduction in cell growth and invasion in vitro (14), and COL11Al knockdown in ovarian cancer cells led to a decrease in cell proliferation and invasion in vitro and the metastasis of an ovarian tumor xenograft (15). Thus, COL11A1 may represent a potential therapeutic target in need of further investigation. 
Considering the limited studies regarding the relationship between COL11Al and GC, we evaluated the COL11Al mRNA expression in GC tissue, investigated the possible role of COL11A1 in GC proliferation, cell cycle, apoptosis and invasion and explored the potential molecular mechanisms of COL11A1 in GC cells in the present study.

\section{Materials and methods}

Ethics statement and clinical tissue samples. This study was approved by the Clinical Research Ethics Committee of Sir Run Run Shaw Hospital of Zhejiang University (Hangzhou, Zhejiang, China) (permit number: 20110225-3200). Giving their informed consents to use their gastric tissue and publish their case details, all 57 consecutive patients who underwent surgery for GC in Sir Run Run Shaw Hospital were enrolled in this study. The histologic classification of gastric carcinoma is based on the 2010 WHO classification system and the clinicopathologic parameters including age, gender, tumor size, depth of invasion and lymph node positivity were obtained. The matched tumor tissues and adjacent non-tumor tissue samples were frozen immediately in liquid nitrogen and were stored at $-80^{\circ} \mathrm{C}$ until RNA extraction.

Cell culture. A total of four poorly differentiated (AGS, MKN-45, BGC-823 and MGC-803), one moderately differentiated (SGC-7901), one undifferentiated (HGC-27) and one well differentiated (MKN-28) gastric cancer cell line were included for the purposes of this study. These cell lines were obtained from the American Type Culture Collection (Manassas, VA, USA) and Type Culture Collection of China Academic Science (Shanghai, China). One normal immortalized gastric epithelial cell line (GES-1) was obtained from the Beijing Institute for Cancer Research (Beijing, China). The cells were cultured in RPMI-1640 medium (Gibco, Carlsbad, CA, USA) supplemented with $10 \%$ fetal bovine serum (FBS) (Sijiqing, Huzhou, Zhejiang, China) and were incubated at $37^{\circ} \mathrm{C}$ in $5 \% \mathrm{CO}_{2}$.

Reverse transcription quantitative PCR (RT-qPCR) analysis. Total RNA was extracted using TRIzol reagent (CW Biotech, Beijing, China), and the reverse transcription reaction was performed using $1 \mu \mathrm{g}$ RNA with a reverse transcription kit (Takara, Otsu, Japan). RT-qPCR reactions were performed using a SYBR green PCR kit (Takara) in a LightCycler ${ }^{\circledR} 480$ II Real-Time PCR System according to the manufacturer's instructions (Roche Diagnostics, Basel, Switzerland). U6 and Glyceraldehyde-3-phosphate dehydrogenase (GAPDH) were used as endogenous controls for tissues and cells, respectively. The RT-qPCR conditions are as follows: one cycle of $95^{\circ} \mathrm{C}$ for $30 \mathrm{sec}, 40$ cycles of $95^{\circ} \mathrm{C}$ for $15 \mathrm{sec}$ and $60^{\circ} \mathrm{C}$ for $60 \mathrm{sec}$, melting curve analysis. The mRNA expression levels were determined using the $2^{-\Delta \mathrm{Ct}}$ method for tissues and the $2^{-\Delta \Delta C t}$ method for cells. The forward primer sequence is 5'-AGTGGCATCGGGTAGCAATCA-3' (located in exon $3-4$, nt 806-826) and the reverse one is 5'-TGTCCC CCTCAAAAACTTCTTCAT-3' (located in exon 4-5, nt 953-976). The other primer sequences for the RT-qPCR assays are listed in Table I. All experiments were performed in triplicate.
Table I. The forward and reverse primer sequences used in experimental procedures.

\begin{tabular}{|c|c|}
\hline Gene name & Primer sequences \\
\hline XIAP & $\begin{array}{l}\text { F: GACAGTATGCAAGATGAGTCAAGTCA } \\
\text { R: GCAAAGCTTCTCCTCTTGCAG }\end{array}$ \\
\hline NEFL & $\begin{array}{l}\text { F: AGCTGGAGGACAAGCAGAAC } \\
\text { R: TGCCATTTCACTCTTTGTGG }\end{array}$ \\
\hline RGS2 & $\begin{array}{l}\text { F: GTTGGGTAGTGAATCAGGAAGC } \\
\text { R: GACCACCTATTCCCTTCTTGC }\end{array}$ \\
\hline ITGB8 & $\begin{array}{l}\text { F: GGCCAAGGTGAAGACAATAGA } \\
\text { R: ATCCTCTTGAACACACCATCC }\end{array}$ \\
\hline WNT5A & $\begin{array}{l}\text { F: ATCAATTCCGACATCGAAGG } \\
\text { R: CGTTCACCACCCCTGCT }\end{array}$ \\
\hline CDK6 & $\begin{array}{l}\text { F: GTGCCCTGTCTCACCCATAC } \\
\text { R: GACCCATAAGCCACCAAGG }\end{array}$ \\
\hline TIAM1 & $\begin{array}{l}\text { F: CAGGTGTTTGGAGAGGGAAC } \\
\text { R: AATGTCGCAGTCAGGGTTG }\end{array}$ \\
\hline U6 & $\begin{array}{l}\text { F: CTCGCTTCGGCAGCACA } \\
\text { R: AACGCTTCACGAATTTGCGT }\end{array}$ \\
\hline GAPDH & $\begin{array}{l}\text { F: GAAGGTGAAGGTCGGAGT } \\
\text { R: GAAGATGGTGATGGGATTTC }\end{array}$ \\
\hline
\end{tabular}

$\mathrm{F}$, forward; $\mathrm{R}$, reverse.

Western blotting. The cells were washed in cold PBS and lysed in RIPA lysis buffer (Beyotime, Jiangsu, China) on ice for $30 \mathrm{~min}$. The cell lysates were centrifuged at $13,000 \mathrm{x} \mathrm{g}$ for $15 \mathrm{~min}$ at $4^{\circ} \mathrm{C}$, and the total protein concentration was analyzed with the BCA Protein Assay kit (Beyotime). Equal amounts of protein samples were separated on sodium dodecyl sulfate-polyacrylamide gel electrophoresis gels (SDS-PAGE). The proteins were then transferred to polyvinylidene difluoride membranes (Millipore, Bedford, MA, USA). The membranes were blocked with 5\% nonfat milk and incubated with primary antibodies at $4{ }^{\circ} \mathrm{C}$ overnight. The proteins were detected using chemiluminescence with a Las-4000 Imaging System (Fujifilm, Tokyo, Japan). The following primary antibodies were used: COL11A1 (1:1000; Abcam, Cambridge, UK), pro-caspase-3 (1:1000; Cell Signaling Technology Inc., Danvers, MA, USA), cleaved caspase-3 (1:1000; Cell Signaling Technology Inc.), cyclin $\mathrm{D}_{1}$ (1:1000; Cell Signaling Technology Inc.), p21 (1:1000; Cell Signaling Technology Inc.), p27 (1:1000; Cell Signaling Technology Inc.), cyclin-dependent kinase 2 (CDK2) (1:500; Santa Cruz Biotechnology Inc., Santa Cruz, CA, USA), cyclin-dependent kinase 4 (CDK4) (1:500; Santa Cruz Biotechnology Inc.) and $\beta$-tubulin (1:1000; CW Biotech). All experiments were performed in triplicate.

Plasmid transfection of stable cell lines. The COL11AI short hairpin RNA (shRNA) plasmids (HSH002603-2-mH1, GeneCopoeia, Rockville, MD, USA) and COL11Al vector plasmids (CSHCTR001-mH1, GeneCopoeia) were purchased 


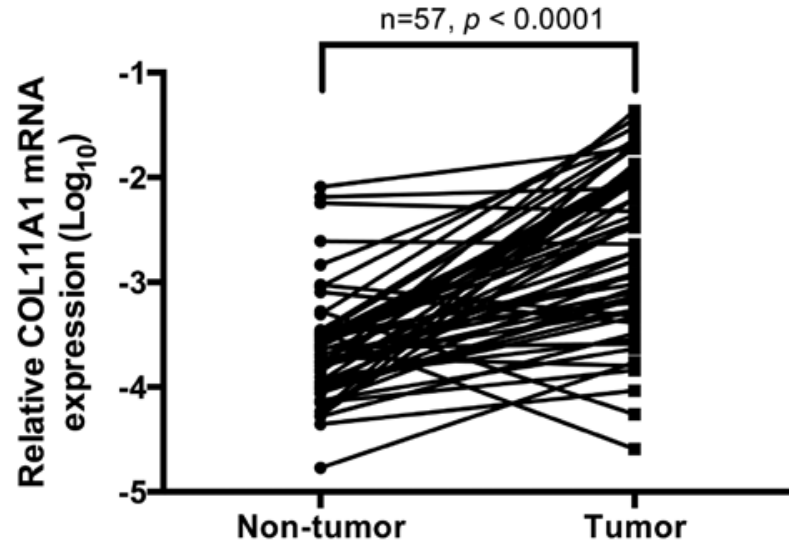

Figure 1. RT-qPCR analysis of COL11A1 mRNA expression in GC patients. The relative expression of COL11A1 mRNA was significantly increased in GC tissues compared with matched adjacent non-tumor tissues by RT-qPCR $(\mathrm{n}=57, \mathrm{p}<0.0001)$.

and transfected into HGC-27 cells using Lipofectamine 2000 (Invitrogen, Carlsbad, CA, USA) to establish stable cell lines. After $48 \mathrm{~h}$, the transfectants were selected with $3 \mu \mathrm{g} / \mathrm{ml}$ puromycin (Amresco, Cleveland, OH, USA) for 2 weeks. A positive stably transfected clone was isolated and allowed to grow. Decreased COL11Al expression was confirmed by RT-qPCR and western blotting. All experiments were performed in triplicate.

Cell proliferation assay. A total of $3 \times 10^{3}$ stably transfected cells in $100 \mu \mathrm{l}$ medium were seeded into 96-well plates and incubated for $96 \mathrm{~h}$. Then, $20 \mu \mathrm{l}$ of 3-(4,5-dimethylthiazol2-yl)-5-(3-carboxymethoxyphenyl)-2-(4-sulfophenyl)-2Htetrazolium (MTS) (Promega, Madison, WI, USA) reagent was added to each well and incubated for $2 \mathrm{~h}$. The absorbance values were measured by a multi-well plate reader (Molecular Devices, Sunnyvale, CA, USA) at $490 \mathrm{~nm}$. All experiments were performed in triplicate.

Colony formation assay. A total of $6 \times 10^{2}$ cells were plated into six-well plates in triplicate. The plates were incubated at $37^{\circ} \mathrm{C}$ in $5 \% \mathrm{CO}_{2}$ for 10 days, and then the colonies were fixed with methanol and stained with crystal violet before counting. Values are presented as the mean percentage \pm SD from three individual experiments, and the number for the COL11AI vector cells was set to $100 \%$. All experiments were performed in triplicate.

Cell migration and invasion assays. Cell migration was assessed using Transwell migration assays (Corning, Inc., Corning, NY, USA). Briefly, $5 \times 10^{4}$ cells were plated in the upper chamber in $200 \mu \mathrm{l}$ medium containing $1 \%$ FBS. The lower chamber contained $600 \mu \mathrm{l}$ medium containing $10 \%$ FBS. After $13 \mathrm{~h}$ of incubation, the non-migratory cells in the upper chamber were carefully removed with a cotton swab. The migrated cells were fixed with methanol and stained with DAPI. The cell numbers were counted in five random fields (x400 magnification) using a fluorescence microscope. All experiments were performed in triplicate.

Cell invasion was performed in Transwell chambers (Corning, Inc.) coated with BD Matrigel. For this assay,
Table II. Clinicopathological characteristics and COL11AI mRNA expression in gastric cancer samples.

\begin{tabular}{|c|c|c|c|}
\hline \multirow[b]{2}{*}{ Variables } & \multicolumn{3}{|c|}{ COL11A1 expression } \\
\hline & Total & $\left(2^{-\Delta \mathrm{Ct}}\right)($ median$)$ & P-value \\
\hline \multicolumn{4}{|l|}{ Age (years) } \\
\hline$\leq 63$ & $27(47 \%)$ & 0.00113 & $0.031^{\mathrm{a}}$ \\
\hline$\geq 64$ & $30(53 \%)$ & 0.00548 & \\
\hline \multicolumn{4}{|l|}{ Gender } \\
\hline Male & $39(68 \%)$ & 0.00193 & 0.352 \\
\hline Female & $18(32 \%)$ & 0.00356 & \\
\hline \multicolumn{4}{|l|}{ Invasion depth } \\
\hline $\mathrm{T}_{2-4}$ & $44(77 \%)$ & 0.00403 & $0.0004^{t}$ \\
\hline $\mathrm{T}_{1}$ & $13(23 \%)$ & 0.000409 & \\
\hline \multicolumn{4}{|l|}{ Tumor size $(\mathrm{cm})$} \\
\hline$<5$ & $27(47 \%)$ & 0.000878 & $0.024^{\mathrm{a}}$ \\
\hline$\geq 5$ & $30(53 \%)$ & 0.00630 & \\
\hline \multicolumn{4}{|c|}{ Degree of differentiation } \\
\hline Poorly & $37(65 \%)$ & 0.00159 & 0.261 \\
\hline Moderately/Well & $20(35 \%)$ & 0.00630 & \\
\hline \multicolumn{4}{|c|}{ Lymph node positivity } \\
\hline Yes & $36(63 \%)$ & 0.00455 & $0.019^{\mathrm{a}}$ \\
\hline No & $21(37 \%)$ & 0.000739 & \\
\hline
\end{tabular}

${ }^{\mathrm{a}} \mathrm{p}<0.05,{ }^{\mathrm{b}} \mathrm{p}<0.01$.

$1 \times 10^{5}$ cells were plated in the upper chamber in $200 \mu 1$ of medium containing $1 \%$ FBS. The lower chamber was filled with $600 \mu \mathrm{l}$ of culture medium with $10 \%$ FBS. After $24 \mathrm{~h}$, the membranes were fixed with methanol and stained with gentian violet. The cell numbers were counted by microscope in five random fields (x200 magnification). All experiments were performed in triplicate.

Cell apoptosis and cell cycle analysis. For cell apoptosis analysis, $2 \times 10^{5}$ stable transfected cells were washed in cold PBS and suspended in 1X Annexin V Binding Buffer. Then, $5 \mu \mathrm{l}$ FITC Annexin V (Becton Dickinson, San Jose, CA, USA) and $5 \mu \mathrm{l}$ PI (Becton Dickinson) solutions were added. After incubation for $15 \mathrm{~min}$, the stained cells were analyzed by flow cytometry on a FACScan analyzer (Becton Dickinson). All experiments were performed in triplicate.

For cell cycle analysis, $2 \times 10^{5}$ stably transfected cells were harvested and washed in PBS. Cellular DNA was stained in the dark by a Cell Cycle Staining kit (Multisciences Biotech, Hangzhou, Zhejiang, China) for $30 \mathrm{~min}$ at room temperature. The cells were then analyzed by flow cytometry, and the cell cycle distribution was determined using ModFit LT software (Verity Software House, Topsham, ME, USA). All experiments were performed in triplicate.

cDNA microarray analysis. Total RNA was extracted from stably transfected HGC-27 cells with COL11Al shRNA and 


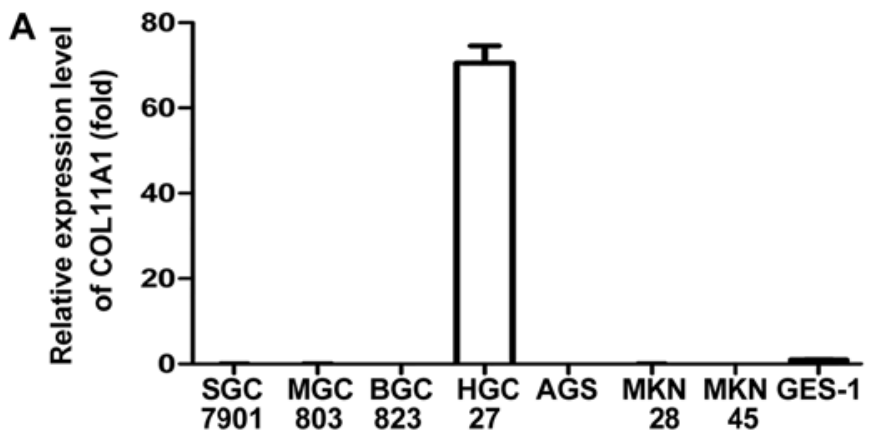

B
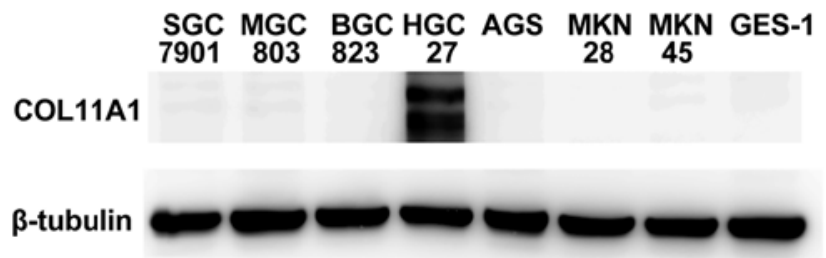

Figure 2. COL11A1 expression in seven GC cell lines compared with normal immortalized epithelial cells (GES-1). (A) The COL11A1 mRNA expression was higher in HGC-27 cells but lower in the other six GC cells (SGC-7901, MGC-803, BGC-823, AGS, MKN-28, and MKN-45) compared with GES-1 by RT-qPCR analysis. (B) COL11A1 protein expression levels were higher in HGC-27 cells but lower in the other six GC cells (SGC-7901, MGC-803, BGC-823, AGS, MKN-28, and MKN-45) compared with GES-1 by western blotting.

Table III. The influences of cell apoptosis and cell cycle by COL11Al knockdown.

\begin{tabular}{lccccc}
\hline Group & $\begin{array}{c}\text { Early apoptotic } \\
\text { cells } \mathrm{A}_{1}(\%)\end{array}$ & $\begin{array}{c}\text { Late apoptotic } \\
\text { cells } \mathrm{A}_{2}(\%)\end{array}$ & $\begin{array}{c}\mathrm{G}_{1} \text { Phase } \\
(\%)\end{array}$ & $\begin{array}{c}\mathrm{S} \text { Phase } \\
(\%)\end{array}$ & $\begin{array}{c}\mathrm{G}_{2} / \mathrm{M} \text { Phase } \\
(\%)\end{array}$ \\
\hline COL11A1 vector & $7.42 \pm 0.89$ & $11.19 \pm 0.25$ & $28.57 \pm 0.24$ & $50.50 \pm 0.48$ & $20.93 \pm 0.25$ \\
COL11A1 shRNA & $14.94 \pm 0.27^{\mathrm{a}}$ & $20.62 \pm 0.21^{\mathrm{a}}$ & $36.34 \pm 0.38^{\mathrm{a}}$ & $50.38 \pm 0.28$ & $13.28 \pm 0.38^{\mathrm{a}}$ \\
\hline
\end{tabular}

${ }^{\mathrm{a}} \mathrm{p}<0.01$.

COL11A1 vector. Total RNA was amplified, labeled and purified to obtain biotin-labeled cDNA. The labeled cDNA were hybridized to probes on Affymetrix U133 plus 2.0 arrays (Shanghai Biotechnology Corporation, Shanghai, China). The microarray data were analyzed using Gene Spring Software 11.0. We selected fold change (shRNA/vector) $>3$ or $<0.333$ as the threshold for upregulation or downregulation. The potential target genes were verified with RT-qPCR.

Statistical analysis. Wilcoxon matched pairs test was performed to compare paired data, Mann-Whitney U test was used to analyze and compare the medians of continuous variables, and Student's t-test was performed to compare two independent data. A value of $\mathrm{p}<0.05$ was considered statistically significant. All data were analyzed using IBM SPSS Statistics 20.0.

\section{Results}

We used RT-qPCR analysis to measure the COL11A1 mRNA expression and found that the COL11A $1 \mathrm{mRNA}$ expression level was significantly overexpressed in $57 \mathrm{GC}$ tissues compared to matched adjacent non-tumor gastric tissue ( $\mathrm{p}<0.0001$, Fig. 1).

In 2/57 patients distant metastases occurred (liver and peritoneum, respectively), and 56/57 patients were diagnosed with gastric cancer of the adenocarcinoma subtype, while the remaining patient was diagnosed with an undifferentiated gastric carcinoma. The relationship between clinicopathological features and COL11Al expression in GC is shown in Table II. COL11A1 mRNA expression was significantly positively related to age, tumor invasion depth, tumor size and lymph node positivity $(\mathrm{p}<0.05, \mathrm{p}<0.01, \mathrm{p}<0.05$ and $\mathrm{p}<0.05$, respectively), while there were no significant associations between COL11Al expression and patient gender $(\mathrm{p}>0.05)$ and degree of differentiation $(\mathrm{p}>0.05)$ in GC.

To determine which cell lines to use for further study, we compared COL11A1 mRNA and protein expression levels in seven GC cell lines (SGC-7901, MGC-803, BGC-823, HGC-27, AGS, MKN-28, and MKN-45) with expression levels in normal immortalized epithelial cells (GES-1) by RT-qPCR and western blotting. The results showed that the relative COL11A1 mRNA expression was higher in HGC-27 cells but lower in the other six GC cells (Fig. 2A), while similar results were observed by western blotting (Fig. 2B). Hence, HGC-27 was the only chosen $\mathrm{GC}$ cell line for further analysis.

To validate whether COL11Al contributed to GC proliferation, migration and invasion, we transfected HGC-27 cells with a plasmid encoding COL11Al-silencing shRNA (COL11Al shRNA) or COL11Al vector shRNA (COL11Al vector). The decreased COL11A1 mRNA and protein expression levels were confirmed by RT-qPCR and western blotting (Fig. 3A).

Then, we examined whether COL11Al contributed to GC cell proliferation. The results of MTS assays showed significant cell growth inhibition in COL11A1 shRNA HGC-27 cells compared with COL11A1 vector cells ( $\mathrm{p}<0.01$ at 48,72 and $96 \mathrm{~h}$ ) (Fig. 3B). Consistently, the number of surviving colonies formed on the plates in COL11Al shRNA HGC-27 cells was also significantly reduced compared with $C O L 11 A 1$ vector cells ( $\mathrm{p}<0.01)$ (Fig. 3C). Thus, COL11Al contributed to cell proliferation in GC cells in vitro.

Next, Transwell migration and invasion assays were performed, and the results demonstrated that COL11Al knockdown in HGC-27 cells significantly suppressed migration $(p<0.01)$ and invasion $(p<0.01)$, respectively (Fig. 3D and E). 
A
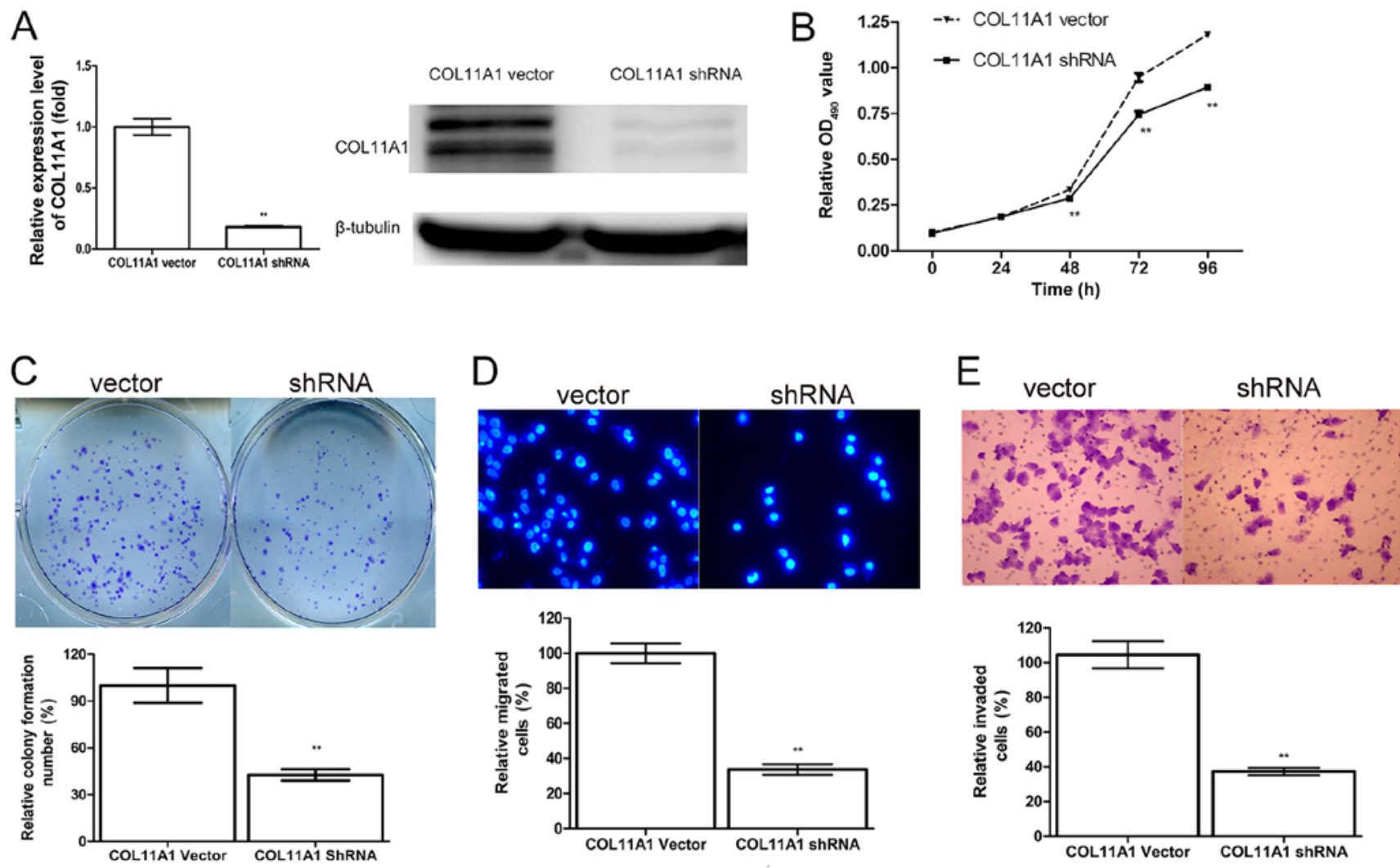

Figure 3. Suppressing COL11A1 inhibits the proliferation, migration and invasion of HGC-27 cells in vitro. (A) Decreased COL11Al expression in HGC-27 GC cells was confirmed by RT-qPCR (left) and western blotting (right). (B) The MTS assays showed that COL11A1 suppression significantly inhibited proliferation. (C) The monolayer colony formation assays showed that COL11Al suppression significantly inhibited proliferation. (D) Transwell migration assays of COL11A1 downregulated HGC-27 cells showed that silencing COL11A1 significantly inhibited cell migration. (E) Transwell invasion assays of COL11A1 downregulated HGC-27 cells showed that suppressing COL11A1 significantly inhibited cell invasion. The asterisk indicates statistical significance ( $\mathrm{p}<0.05$, $\left.{ }^{* *} \mathrm{p}<0.01\right)$.

Cumulatively, these results indicated that COL11Al played a role in cell proliferation, migration and invasion of HGC-27 $\mathrm{GC}$ cells in vitro.

To explore the underlying mechanisms of the growth inhibition by COL11A1 knockdown, we assessed cell apoptosis and cell cycle by flow cytometry. COL11Al suppression significantly induced apoptosis compared with COL11AI vector (Fig. 4A and Table III), and a significant accumulation of cells in $\mathrm{G}_{1}$ phase was observed in COL11Al knockdown cells compared to that in COL11Al vector cells (Fig. 4B and Table III). Then, we further evaluated expression levels of several cell cycle and apoptosis-related proteins, and we found that COL11A1 suppression led to upregulation of the cell cycle inhibitor $\mathrm{p} 21$ but not $\mathrm{p} 27$ and reduced cyclin $\mathrm{D}_{1}$ but not CDK2 and CDK4. We also found activation of the apoptotic protein caspase-3 (Fig. 4C).

cDNA microarray in HGC-27 cells with and without COL11A1 knockdown was performed to identify potential downstream genes of COL11Al in GC, and the results indicated that COL11A1 suppression altered the expression of multiple genes involved in cell proliferation and invasion (Fig. 5A). The results of RT-qPCR further confirmed that CDK6, TIAM1, $X I A P, I T G B 8$ and $W N T 5 A$ were downregulated, and RGS2 and $N E F L$ were upregulated by COL11A1 suppression in HGC-27 cells (Fig. 5B). These results suggested that COL11A1 may play a role in tumor development and progression through regulation of these genes.

\section{Discussion}

The gradual accumulation of genetic alternations contributes to the development and progression of cancers. In the present study, we observed that overexpression of COL11A1 mRNA was related to tumor age, tumor size, depth of invasion and lymph node positivity, and that COL11Al could regulate cell proliferation, migration and invasion through several potential downstream genes.

Several lines of evidence indicate that COL11A1 expression is upregulated in various cancers such as ovarian (15), colorectal (10), breast (13), pancreatic (16) and head and neck squamous cell (14) cancers, suggesting an oncogenic role of COL11A1 in carcinogenesis. However, the role of COL11A1 in $\mathrm{GC}$ has not been elucidated. This study demonstrated that COL11A1 mRNA was overexpressed in $57 \mathrm{GC}$ tissues compared with matched non-tumor tissues by RT-qPCR analysis, which is consistent with previous studies (4). In addition, we analyzed the relationship between COL11A1 mRNA expression and clinicopathological characteristics. Consistent with a previous report in GC by Affymetrix analysis (17), COL11A1 mRNA expression in the advanced GC was significantly higher than that in the early GC. Besides, high COL11Al expression was positively related to tumor age, tumor size and lymph node positivity, which indicates COL11Al may be involved in GC growth and invasion. These results supports that COL11A1 may play a role in GC proliferation and invasion. 

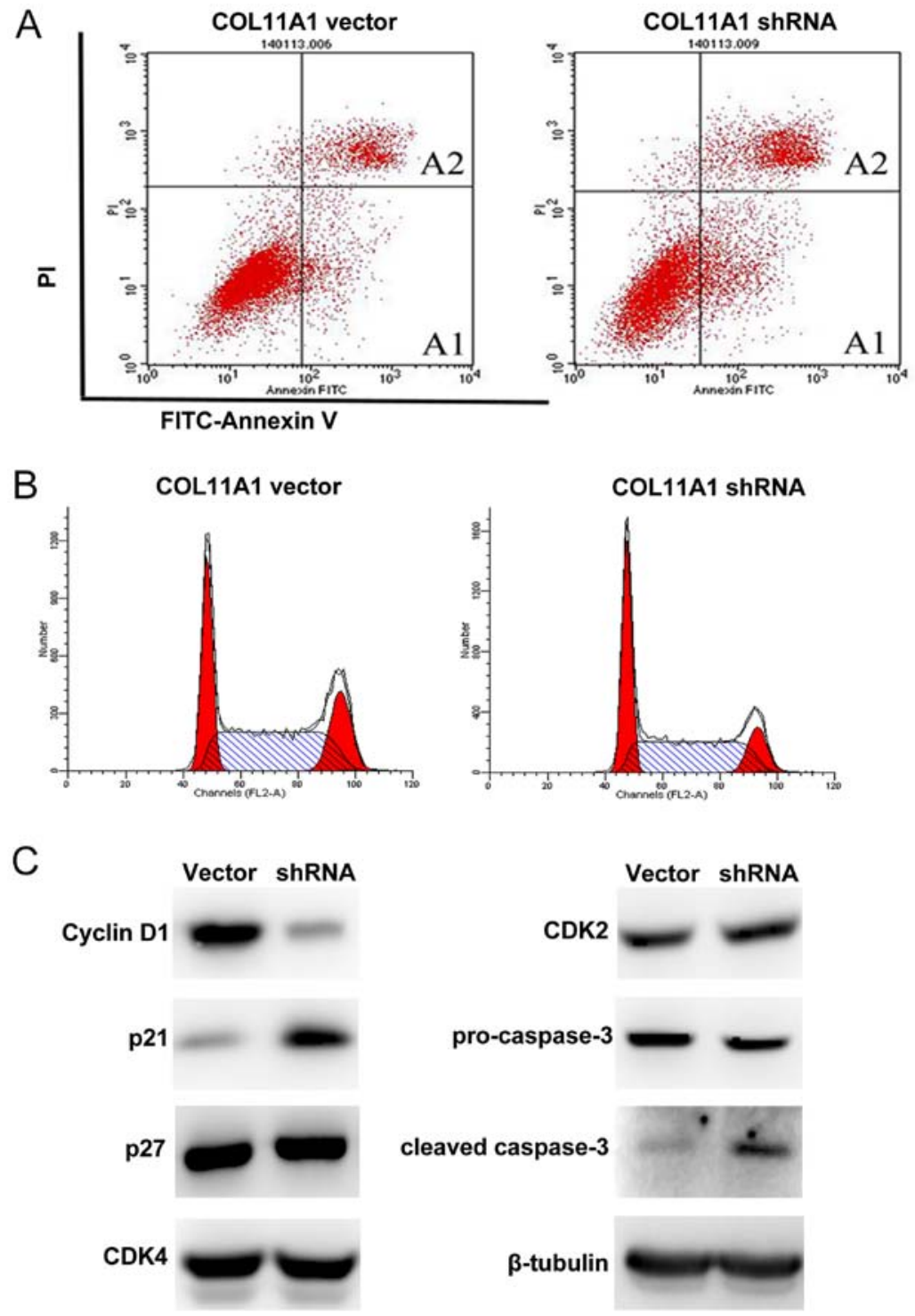

Figure 4. COL11A1 suppression induces cell apoptosis and cell cycle inhibition in HGC-27 cells. (A) The rate of cell apoptosis was increased in cells with COL11A1 suppression. Region $\mathrm{A}_{1}$ indicates early apoptotic cells, while region $\mathrm{A}_{2}$ indicates late apoptotic cells. (B) Suppression of COL11A1 significantly increased the proportion of cells at $\mathrm{G}_{1}$ phase from $28.57 \pm 0.24 \%$ to $36.34 \pm 0.38 \%$. (C) COL11A1 suppression arrested cells at $\mathrm{G}_{1}$ phase of the cell cycle by downregulating protein expression of cyclin $\mathrm{D}_{1}$ and upregulating protein expression of $\mathrm{p} 21$, while induced apoptosis by upregulating protein expression of cleaved caspase-3. Band densities were normalized to $\beta$-tubulin expression.

To study the biological effects of COL11Al in GC, we examined COL11Al expression in seven GC cell lines and one GES-1 cell line and found that HGC-27 was the only cell line showing COL11A1 upregulation compared to GES-1. The reason why COL11Al is overexpressed in only one cancer cell line, out of seven, compared to normal cells needs further explanation. From our perspective, one explanation may be that HGC-27, a kind of undifferentiated and relatively less attached cell, is much more aggressive than the other six cells. Finally, we chose HGC-27 for the next study.

Based on depletion experiments in vitro, we found that silencing of COL11A1 significantly decreased the proliferation, migration and invasion of HGC-27 cells, which is consistent with two previous reports in ovarian cancer (15) and head and neck squamous cell cancer (14). Furthermore, we studied the cell cycle and apoptosis using flow cytometry, and the results showed that COL11Al suppression significantly induced cell cycle arrest at $G_{1}$ phase and promoted cell apoptosis. $G_{1} / S$ phase transition is a major checkpoint for cell cycle progression. Cyclin $\mathrm{D}_{1}$, forming functional kinase complexes with CDK4 or CDK6, is a periodic regulatory protein that governs cell cycle transit from $\mathrm{G}_{1}$ phase into $\mathrm{S}$ phase and is abnormally expressed in many human cancers $(18,19)$. There are also inhibitory proteins preventing the cell cycle. Among these inhibitors, p21, a potent cyclin-dependent kinase inhibitor binds and inhibits the activity of cyclin $\mathrm{D}_{1}$-CDK4/6 complexes controlling the transition from $G_{1}$ to $S$ phase (20). In the present study, western blotting demonstrated that suppression of COL11Al decreased cyclin $\mathrm{D}_{1}$ expression and increased $\mathrm{p} 21$ expression. However, there was no significant effect on CDK2, CDK4 or p27. These results suggest that $\mathrm{G}_{1} / \mathrm{S}$ cell cycle arrest induced by COL11A1 suppression is mediated through the p21 and cyclin $\mathrm{D}_{1}$ pathway. In addition, caspase-3 is a well-recognized indicator of cellular apoptosis (21) and is activated in apoptotic cells by both the extrinsic and intrinsic pathways (22). Our data indicated that COL11A1 suppression increased cleaved caspase-3 levels in 

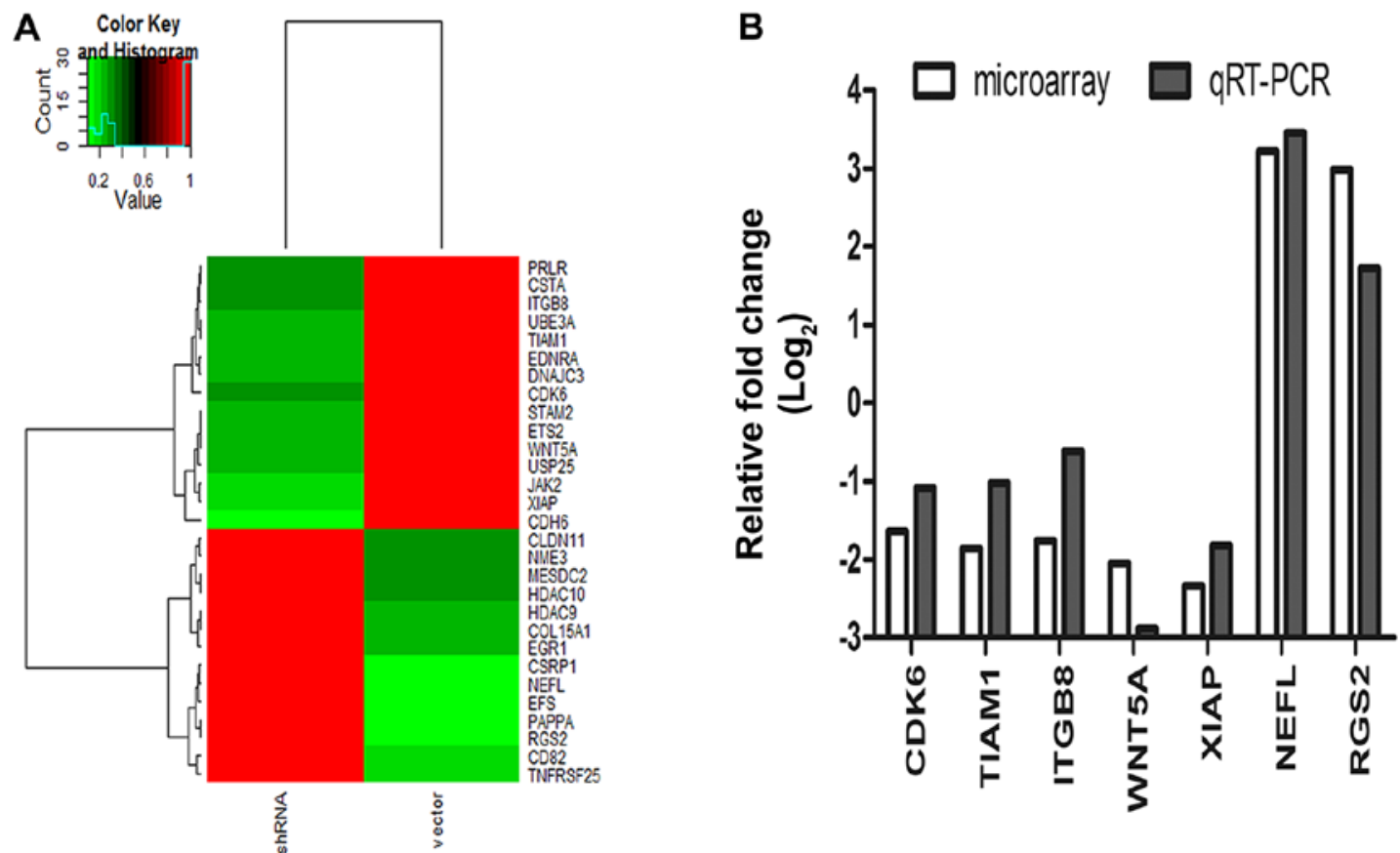

Figure 5. Gene expression changes by COL11A1 suppression in HGC-27 cells. (A) The representative gene expression profiles in HGC-27 cells with stably transfected COL11A1 shRNA compared with COL11A1 vector are indicated on the right side of this heatmap image. Green indicates small values, progressing to red for higher values. (B) The expression of nine potential target genes was verified by RT-qPCR. $\log _{2}$ fold change of relative expression levels in $C O L 11 \mathrm{Al}$ shRNA HGC-27 cells were compared with that in COL11Al vector, which was normalized to 1. $\square$, RT-qPCR data; $\mathbf{m}$, results of cDNA microarray.

HGC-27 cells, and thus promoted apoptosis of HGC-27 cells. Further studies are required to determine whether the extrinsic or intrinsic pathway is involved. Despite several attempts, we failed to establish a successful nude mouse model to investigate the role of COL11A1 in vivo.

The molecular mechanisms of COL11A1 action in cancers remain unclear, and the only pathway studied is the COL11A1TGF- $\beta 1-M M P 3$ axis through which COL11A1 promotes ovarian cancer aggressiveness. Therefore, we studied the molecular mechanisms of COL11A1 in GC by cDNA microarray. Numerous genes were altered in cells with COL11AI knockdown compared to cells with $C O L 11 A 1$ vector, and the representative potential target genes have been previously reported to participate in cell growth, migration and invasion. As a member of the inhibitor of apoptosis protein gene family, XIAP can inhibit caspases and suppress apoptosis, and a previous study showed that downregulation of XIAP induced apoptosis was related to activation of caspase-3 in GC (23). $C D K 6$, important for the $\mathrm{G}_{1}$ phase progression and $\mathrm{G}_{1} / \mathrm{S}$ transition, was upregulated in many cancers (24). Another COL11A1 potential target gene, $R G S 2$, was also involved in cell growth in breast cancer (25) and prostate cancer (26). In addition to the regulation of cell proliferation pathways, COL11AI downregulation decreased TIAMI which was involved in cell invasion in retinoblastoma (27) and gastric cancer (28). Furthermore, $N E F L$, a putative tumor suppressor gene, can inhibit cell proliferation and invasion in head and neck squamous cell carcinoma (29) and neuroblastoma (30). We further validated that CDK6, TIAM1, XIAP, ITGB8 and WNT5A were downregulated, while $R G S 2$ and $N E F L$ were upregulated in HGC-27 cells with COL11A1 suppression using RT-qPCR analysis. Thus, the identification of potential target genes of COL11Al supported the hypothesis that COL11A1 may modu- late potential downstream genes to regulate cell proliferation and invasion in GC.

In conclusion, our study indicates that $C O L 11 A 1$ may play an oncogenic role in the proliferation, migration and invasion in gastric cancer and may be a promising therapeutic target in cancer treatment. Further study is needed to clarify the potential specific molecular mechanisms of COL11A1 in gastric cancer.

\section{Acknowledgements}

This study was supported by the National Natural Science Foundation of China (81101836, 81372623), Zhejiang Province Key Science and Technology Innovation Team (2013TD13), and Zhejiang Province medicine health platform and study plan (YH52013004).

\section{References}

1. Ferlay J, Soerjomataram I, Dikshit R, Eser S, Mathers C, Rebelo M, Parkin DM, Forman D and Bray F: Cancer incidence and mortality worldwide: Sources, methods and major patterns in GLOBOCAN 2012. Int J Cancer 136: E359-E386, 2015.

2. Rohatgi PR, Yao JC, Hess K, Schnirer I, Rashid A, Mansfield PF, Pisters PW and Ajani JA: Outcome of gastric cancer patients after successful gastrectomy: Influence of the type of recurrence and histology on survival. Cancer 107: 2576-2580, 2006.

3. Vogelstein B and Kinzler KW: The multistep nature of cancer. Trends Genet 9: 138-141, 1993.

4. Zhao Y, Zhou T, Li A, Yao H, He F, Wang L and Si J: A potential role of collagens expression in distinguishing between premalignant and malignant lesions in stomach. Anat Rec (Hoboken) 292: 692-700, 2009.

5. Yoshioka H, Greenwel P, Inoguchi K, Truter S, Inagaki Y, Ninomiya $\mathrm{Y}$ and Ramirez F: Structural and functional analysis of the promoter of the human alpha 1(XI) collagen gene. J Biol Chem 270: 418-424, 1995. 
6. Richards AJ, Yates JR, Williams R, Payne SJ, Pope FM, Scott JD and Snead MP: A family with Stickler syndrome type 2 has a mutation in the COL11A1 gene resulting in the substitution of glycine 97 by valine in alpha 1 (XI) collagen. Hum Mol Genet 5 : 1339-1343, 1996.

7. Khalifa O, Imtiaz F, Allam R, Al-Hassnan Z, Al-Hemidan A, Al-Mane K, Abuharb G, Balobaid A, Sakati N, Hyland J, et al: A recessive form of Marshall syndrome is caused by a mutation in the COL11A1 gene. J Med Genet 49: 246-248, 2012.

8. Griffith AJ, Sprunger LK, Sirko-Osadsa DA, Tiller GE, Meisler MH and Warman ML: Marshall syndrome associated with a splicing defect at the COL11A1 locus. Am J Hum Genet 62: 816-823, 1998

9. Mio F, Chiba K, Hirose Y, Kawaguchi Y, Mikami Y, Oya T, Mori M, Kamata M, Matsumoto M, Ozaki K, et al: A functiona polymorphism in COL11A1, which encodes the alpha 1 chain of type XI collagen, is associated with susceptibility to lumbar disc herniation. Am J Hum Genet 81: 1271-1277, 2007.

10. Fischer H, Stenling R, Rubio C and Lindblom A: Colorectal carcinogenesis is associated with stromal expression of COL11A1 and COL5A2. Carcinogenesis 22: 875-878, 2001.

11. Badea L, Herlea V, Dima SO, Dumitrascu T and Popescu I: Combined gene expression analysis of whole-tissue and microdissected pancreatic ductal adenocarcinoma identifies genes specifically overexpressed in tumor epithelia. Hepatogastroenterology 55: 2016-2027, 2008.

12. Chong IW, Chang MY, Chang HC, Yu YP, Sheu CC, Tsai JR, Hung JY, Chou SH, Tsai MS, Hwang JJ, et al: Great potential of a panel of multiple hMTH1, SPD, ITGA11 and COL11A1 markers for diagnosis of patients with non-small cell lung cancer. Oncol Rep 16: 981-988, 2006.

13. Feng Y, Sun B, Li X, Zhang L, Niu Y, Xiao C, Ning L, Fang Z, Wang Y, Zhang L, et al: Differentially expressed genes between primary cancer and paired lymph node metastases predict clinical outcome of node-positive breast cancer patients. Breast Cancer Res Treat 103: 319-329, 2007.

14. Sok JC, Lee JA, Dasari S, Joyce S, Contrucci SC, Egloff AM, Trevelline BK, Joshi R, Kumari N, Grandis JR, et al: Collagen type XI $\alpha 1$ facilitates head and neck squamous cell cancer growth and invasion. Br J Cancer 109: 3049-3056, 2013.

15. Wu YH, Chang TH, Huang YF, Huang HD and Chou CY: COL11A1 promotes tumor progression and predicts poor clinical outcome in ovarian cancer. Oncogene 33: 3432-3440, 2014

16. García-Pravia C, Galván JA, Gutiérrez-Corral N, Solar-García L, García-Pérez E, García-Ocaña M, Del Amo-Iribarren J, Menéndez-Rodríguez P, García-García J, de Los Toyos JR, et al: Overexpression of COL11A1 by cancer-associated fibroblasts: Clinical relevance of a stromal marker in pancreatic cancer. PLoS One 8: e78327, 2013.

17. Vecchi M, Nuciforo $P$, Romagnoli S, Confalonieri S, Pellegrini C Serio G, Quarto M, Capra M, Roviaro GC, Contessini Avesani E, et al: Gene expression analysis of early and advanced gastric cancers. Oncogene 26: 4284-4294, 2007.
18. Hunter T and Pines J: Cyclins and cancer. II: Cyclin D and CDK inhibitors come of age. Cell 79: 573-582, 1994.

19. Kozar K and Sicinski P: Cell cycle progression without cyclin D-CDK4 and cyclin D-CDK6 complexes. Cell Cycle 4: 388-391, 2005.

20. Yoon MK, Mitrea DM, Ou L and Kriwacki RW: Cell cycle regulation by the intrinsically disordered proteins $\mathrm{p} 21$ and $\mathrm{p} 27$. Biochem Soc Trans 40: 981-988, 2012.

21. Salvesen GS: Caspases: Opening the boxes and interpreting the arrows. Cell Death Differ 9: 3-5, 2002.

22. Ghavami S, Hashemi M, Ande SR, Yeganeh B, Xiao W, Eshraghi M, Bus CJ, Kadkhoda K, Wiechec E, Halayko AJ, et al: Apoptosis and cancer: Mutations within caspase genes. J Med Genet 46: 497-510, 2009.

23. Tong QS, Zheng LD, Wang L, Zeng FQ, Chen FM, Dong JH and Lu GC: Downregulation of XIAP expression induces apoptosis and enhances chemotherapeutic sensitivity in human gastric cancer cells. Cancer Gene Ther 12: 509-514, 2005.

24. Wiedemeyer WR, Dunn IF, Quayle SN, Zhang J, Chheda MG, Dunn GP, Zhuang L, Rosenbluh J, Chen S, Xiao Y, et al: Pattern of retinoblastoma pathway inactivation dictates response to CDK4/6 inhibition in GBM. Proc Natl Acad Sci USA 107: 11501-11506, 2010.

25. Lyu JH, Park DW, Huang B, Kang SH, Lee SJ, Lee C, Bae YS, Lee JG and Baek SH: RGS2 suppresses breast cancer cell growth via a MCPIP1-dependent pathway. J Cell Biochem 116: 260-267, 2015.

26. Wolff DW, Xie Y, Deng C, Gatalica Z, Yang M, Wang B, Wang J, Lin MF, Abel PW and Tu Y: Epigenetic repression of regulator of G-protein signaling 2 promotes androgen-independent prostate cancer cell growth. Int J Cancer 130: 1521-1531, 2012.

27. Subramanian N, Navaneethakrishnan S, Biswas J, Kanwar RK, Kanwar JR and Krishnakumar S: RNAi mediated Tiam1 gene knockdown inhibits invasion of retinoblastoma. PLoS One 8: e70422, 2013

28. Zhu JM and Yu PW: Downregulation of T-cell lymphoma invasion and metastasis-inducing factor 1 induces cytoskeletal rearrangement and inhibits the invasive capacity of gastric cancer cells. Mol Med Rep 8: 425-433, 2013.

29. Huang Z, Zhuo Y, Shen Z, Wang Y, Wang L, Li H, Chen J and Chen W: The role of NEFL in cell growth and invasion in head and neck squamous cell carcinoma cell lines. J Oral Pathol Med 43: 191-198, 2014.

30. Capasso M, Diskin S, Cimmino F, Acierno G, Totaro F, Petrosino G, Pezone L, Diamond M, McDaniel L, Hakonarson H, et al: Common genetic variants in NEFL influence gene expression and neuroblastoma risk. Cancer Res 74: 6913-6924, 2014. 